\title{
Involvement of endoplasmic reticulum stress in adenosine-induced human hepatoma HepG2 cell apoptosis
}

\author{
LING-FEI WU $^{1}$, YAN-QING YE ${ }^{1}$, GUAN-YOU HUANG ${ }^{2}$, HONG-BIAO LI $^{1}$, \\ GUO-PING LI ${ }^{1}$, ZE-JIN PU ${ }^{1}$, BI-LIU WEI ${ }^{1}$ and JIA-LIN FENG ${ }^{3}$ \\ Departments of ${ }^{1}$ Gastroenterology, ${ }^{2}$ Obstetrics and Gynecology, and ${ }^{3}$ Information, \\ Second Affiliated Hospital, Shantou University Medical College, Shantou 515041, P.R. China
}

Received February 7, 2011; Accepted March 10, 2011

DOI: 10.3892/or.2011.1247

\begin{abstract}
Endoplasmic reticulum stress (ERS)-mediated cell apoptosis has been implicated in the development of multiple diseases such as cancer, neurodegenerative diseases and ischemic reperfusion damage. Previous studies have demonstrated the adenosine-induced apoptosis in several tumor cell lines. However, the role of ERS in adenosine-induced human hepatoma HepG2 cell apoptosis remains unclear. The present study was designed to determine whether ERS is involved in adenosine-induced HepG2 cell apoptosis. The MTT assay was used to determine proliferation, and DAPI staining of cell nuclei was performed to determine cell apoptosis. The translocation of CHOP and caspase- 3 was observed by immunofluorescence analysis, and the protein expression of CHOP, caspase- 4 and caspase-3 was detected by Western blotting. The MTT assay demonstrated that adenosine inhibited HepG2 cell proliferation in a dose-dependent manner. DAPI staining of cell nuclei and cell cycle analysis verified cell apoptosis. The immunofluorescence assay demonstrated that adenosine induced the translocation of CHOP and of caspase- 3 from the cytoplasm to the nucleus. Western blotting confirmed that CHOP, caspase-4 and caspase-3 were up-regulated in HepG2 cells after treatment with adenosine. However, JNK protein expression was not altered. These results show that ERS is involved in the adenosine-induced HepG2 cell apoptosis.
\end{abstract}

\section{Introduction}

Recent studies have shown that apoptosis plays an important role in tumor chemotherapy. Apoptosis is an organized programmed and energy-dependent cell death. The apoptotic process includes chromatin margination, nuclear condensation

Correspondence to: Dr Ling-Fei Wu, Department of Gastroenterology, Second Affiliated Hospital, Shantou University Medical College, Shantou 515041, P.R. China

E-mail: lingfeiwu@21cn.com

Key words: adenosine, apoptosis, endoplasmic reticulum stress, glucose-regulated protein 78, C/EBP homologous protein, caspase and fragmentation, followed by the formation of apoptotic bodies (1). Apoptosis is different from necrosis, and does not involve the inflammation response (2). Up to now, three predominant apoptotic pathways, namely the death receptormediated extrinsic pathway, the mitochondria-mediated intrinsic pathway, and the endoplasmic reticulum stress (ERS)mediated pathway have been elucidated (3). Several drugs, such as DDP and 5-Fu, which can induce tumor cell apoptosis have been used in the clinical setting $(4,5)$.

Adenosine, a metabolite of ATP, regulates cardiovascular and immunity functions under normal states (6). However, a high concentration of adenosine has been verified to exert cytotoxicity in several cell lines $(7,8)$. Apoptosis has been reported in several adenosine-induced tumor cell lines (9-11), and in our previous studies, apoptosis occurred in adenosineinduced HepG2 cell lines $(12,13)$. However, the mechanisms of adenosine's effects are still unclear.

The endoplasmic reticulum (ER) is a subcellular organelle where protein folding and modification and calcium storage occur (14). ERS-induced apoptosis has been implicated in several diseases such as diabetes mellitus, Parkinson's disease (15) and has been demonstrated in some tumor cell lines such as PC-12 neuronal cells (16) and lung carcinoma A-549 cells (17). Some drugs, ischemia-reperfusion, hypoxia and glucose starvation can disturb ER function and may lead to ERS (18-20). ERS initiates the unfolded protein response (UPR), which alleviates protein overload in the ER (21). There are three effects of the UPR activation: i) a decrease in the total protein synthesis (22); ii) an increase in the expression of chaperone proteins, such as the glucose-regulated protein 78 (GRP78/BiP), which can complex with the unfolded proteins causing their translocation from the ER to the cytoplasm (23); and iii) an increase in the degradation of the unfolded proteins. Activation of the UPR induces an adaptive response in which the cell attempts to overcome the accumulation of misfolded proteins and the ERS (21). In certain cases, however, the activation of the UPR may be insufficient to overcome ERS, ultimately leading to apoptosis (24). In mammals, there are three ER-resident transmembrane proteins, PERK, ATF6 and IRE1, which can sense the apoptotic signals (25). When PERK, ATF6 and IRE1 are active, they up-regulate the C/EBP homologous protein transcription factor (CHOP) expression. $\mathrm{CHOP}$ regulates apoptosis-related gene expression and induces 
cell apoptosis (26). ERS-mediated apoptosis through the JNK or caspase-4 pathways have also been reported (27-29).

In previous studies, we and other scholars demonstrated that adenosine-induced HepG2 cell apoptosis was related to adenosine transfer into cells that did not occur through the adenosine receptors $(12,13,29)$. Furthermore, we observed that activation of caspase- 3 is indispensable, while that of caspases 8 or 9 is not obvious in the early stage of apoptosis $(12,13)$. We speculated that ERS might be involved in the adenosineinduced HepG2 cell apoptosis. To verify this hypothesis, we investigated the effects of adenosine on ERS-related protein expression in HepG 2 cells. The results demonstrate that adenosine dose-dependently inhibits HepG2 cell proliferation through cell apoptosis, and that ERS-related protein expression, such as that of CHOP, caspase-4 and caspase-3 was up-regulated, while JNK expression was not altered. Taken together, our results demonstrate that ERS is involved in the adenosine-induced HepG2 cell apoptosis.

\section{Materials and methods}

Materials. Dulbecco's modified Eagle's medium (DMEM) was obtained from Gibco Invitrogen Corporation (Carlsbad, CA). Adenosine was purchased from Tree Tech (China). 4',6-Diamidino-2-phenylindol dihydrochloride (DAPI) and propidium iodide (PI) were obtained from Sigma. Primary antibodies against $\beta$-actin, caspase-4, caspase-3, JNK and CHOP were obtained from Santa Cruz Biotechnology (Santa Cruz, CA). The anti-mouse secondary antibody was purchased from KPL (USA). The anti-rabbit secondary antibody was purchased from Sigma. Alexa Fluor 555-labeled donkey anti-rabbit $\mathrm{IgG}$ was purchased from Invitrogen Corporation. Avidin-biotin-horseradish peroxidase complex was purchased from Vector Laboratories, Inc. (USA). Enhanced chemiluminescence detection reagent (ECL kit) was purchased from Pierce (Thermo Scientific, USA). Other materials such as SDS and $\mathrm{NaCl}$ were obtained form Shanghai Sangon Biological Engineering Technology Services Co., Ltd. (China). For the experiments, $10 \mathrm{mmol} / \mathrm{l}$ adenosine was dissolved in DMEM; $2 \%$ bovine serum albumin (BSA), $4 \%$ paraformaldehyde and $0.2 \%$ Triton $\mathrm{X}-100$ were dissolved in the phosphate-buffered saline (PBS).

Cell culture and treatment. Human hepatoma HepG2 cells were used in this study. Cells were cultured in DMEM, supplemented with $10 \%$ fetal bovine serum, $100 \mathrm{U} / \mathrm{ml}$ penicillin, $100 \mathrm{mg} / \mathrm{ml}$ streptomycin, and $5 \% \mathrm{CO}_{2}, 95 \%$ humidity at $37^{\circ} \mathrm{C}$. Cells were detached by $0.25 \%$ trypsin/0.02\% EDTA. For the immunofluorescence assay and DAPI staining, cells were cultured on coverslips in DMEM for $24 \mathrm{~h}$ before addition of adenosine.

MTT assay. The viability assays of HepG2 cells was evaluated with the MTT assay. Briefly, $\sim 5 \times 10^{3}$ HepG2 cells were seeded in a well with $200 \mu 1$ medium cultured in 96-well plates. After the cells were attached, the medium was replaced with different concentrations of adenosine ( 0 to $6 \mathrm{mmol} / \mathrm{l})$ in culture medium. After culturing for $36 \mathrm{~h}$, the cells were incubated with $20 \mu \mathrm{l}$ MTT $(5 \mathrm{~g} / \mathrm{l})$ for another $4 \mathrm{~h}$ in a $5 \% \mathrm{CO}_{2}$ incubator. The medium was then removed and $150 \mu \mathrm{l}$ DMSO were added to each well, followed by thermal agitation for $5 \mathrm{~min}$ protected

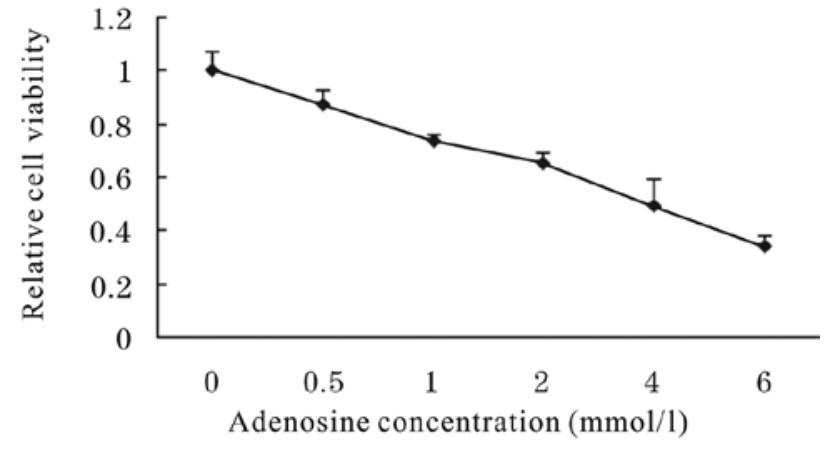

Figure 1. Dose-dependent effect of adenosine on the inhibition of HepG2 cell proliferation. HepG2 cells were exposed to different concentrations of adenosine (range, 0-6.0 mmol/l). After incubation for $36 \mathrm{~h}$, the viability of HepG2 cells was evaluated by the MTT assay. The data are presented as the means \pm SD. Independent experiments were repeated three times.

from light. The absorbance of each well was measured with a microtiter plate reader (KHB Labsystems Wellscan K3, Finland) at $492 \mathrm{~nm}$.

Apoptotic nuclei staining. DAPI is a fluorescent dye which specifically conjugates to ds-DNA and is thus used to visualize nuclear morphological features; the nuclei of apoptotic cells demonstrate condensation and fragmentation. Cells were fixed in $4 \%$ paraformaldehyde for $30 \mathrm{~min}$ at room temperature and then permeabilized with $0.2 \%$ Triton X-100 in PBS for $5 \mathrm{~min}$ at room temperature. DAPI $(500 \mathrm{ng} / \mathrm{ml})$ staining was performed at room temperature for $10 \mathrm{~min}$. The morphology of the nuclei was viewed and captured with a fluorescence microscope (Olympus BX51, Japan).

Flow cytometry. HepG2 cells were harvested and washed three times in cold PBS. The cells were fixed in $70 \%$ ethanol at $-20^{\circ} \mathrm{C}$ overnight and then washed in PBS to remove the ethanol. The cells were treated with RNase $(50 \mu \mathrm{g} / \mathrm{ml})$ and stained with PI $(50 \mu \mathrm{g} / \mathrm{ml})$ for $30 \mathrm{~min}$ at $37^{\circ} \mathrm{C}$ protected from light. Cellular fluorescence was measured by FCM analysis by a FACScan apparatus (Becton-Dickinson, Heidelberg, Germany).

Immunofluorescence microscopy. For immunofluorescence analysis, cells were fixed in $4 \%$ paraformaldehyde for $30 \mathrm{~min}$ and permeabilized in $0.2 \%$ Triton $\mathrm{X}-100$ for $10 \mathrm{~min}$ at room temperature, then blocked with $2 \%$ BSA for $30 \mathrm{~min}$. Subsequently, the cells were incubated with primary antibodies against caspase-3 (1:100) or CHOP (1:100) or with PBS (blank group) at $4^{\circ} \mathrm{C}$ overnight. The next day, HepG2 cells were incubated with the Alexa Fluor 555-labeled donkey antirabbit $\operatorname{IgG}(1: 100)$ for $60 \mathrm{~min}$ at $37^{\circ} \mathrm{C}$. The cell nuclei were stained with DAPI for $10 \mathrm{~min}$. The cells were viewed and captured with a fluorescence microscope (Olympus BX51).

Western blot analysis. Cells were washed with PBS, harvested and lysed in RIPA buffer containing $1 \%$ sodium deoxycholine, $0.1 \%$ SDS, $1 \%$ Triton X-100, 10 mM Tris-HCl (pH 8.0), $0.14 \mathrm{M}$ $\mathrm{NaCl}$ and $0.5 \% \mathrm{NP}-40$. Equal amounts of protein were separated by $12 \%$ SDS-PAGE and transferred to a nitrocellulose membrane (Pall Corporation, NY). The membranes were blocked with $5 \%$ non-fat milk for $30 \mathrm{~min}$ at room temperature, 

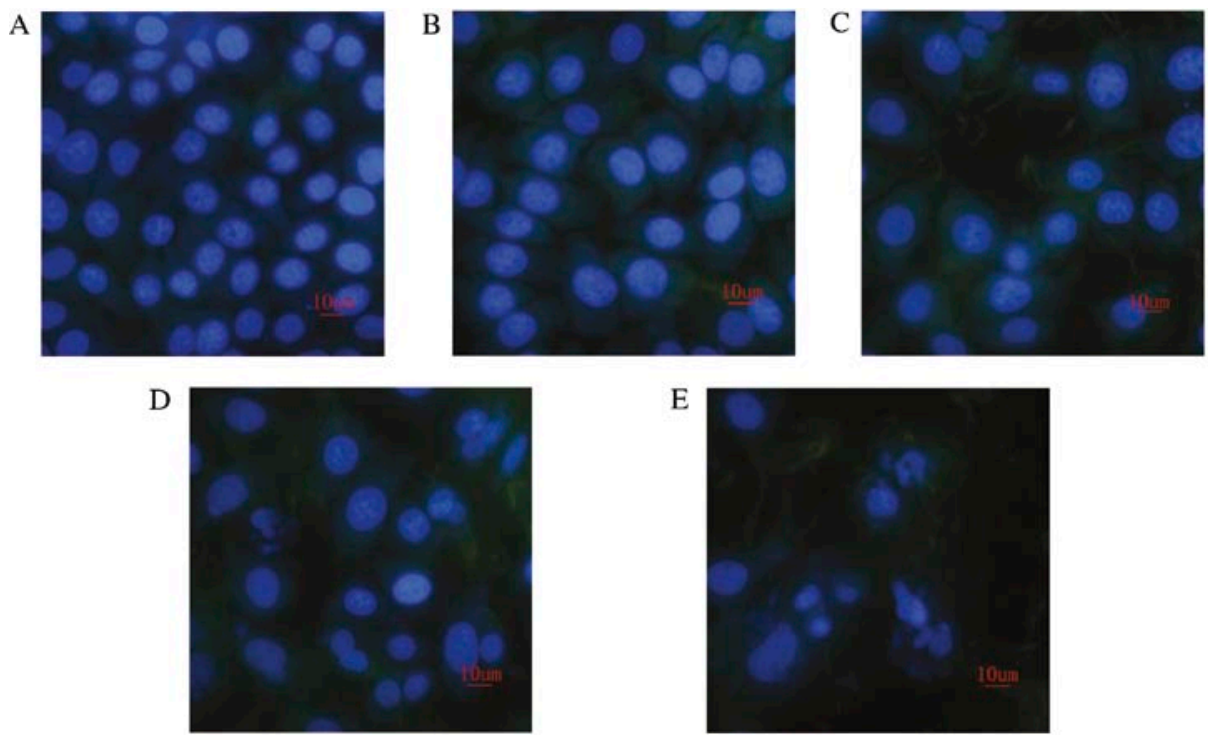

Figure 2. Adenosine induces apoptosis in HepG2 cells in a dose-dependent manner. HepG2 cells were exposed to different concentrations of adenosine (range, 0-4.0 mmol/l). After incubation for $36 \mathrm{~h}$, the nuclei stained by DAPI were observed under a fluorescence microscope. (A) Control ( $0 \mathrm{mmol} / \mathrm{l}$ ); (B) $0.5 \mathrm{mmol} / 1$; (C) $1.0 \mathrm{mmol} / 1$; (D) $2.0 \mathrm{mmol} / 1$; (E) $4.0 \mathrm{mmol} / 1$.

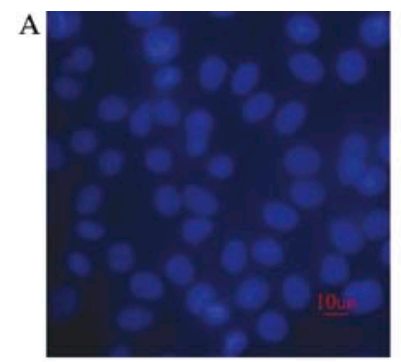

D

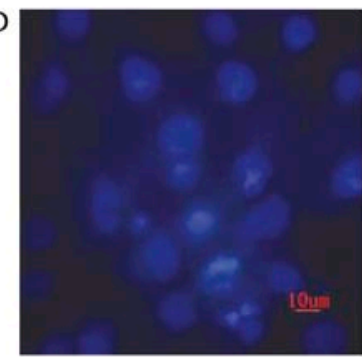

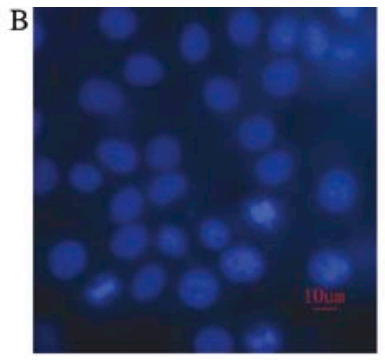

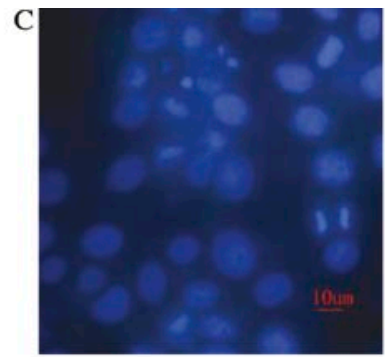

E

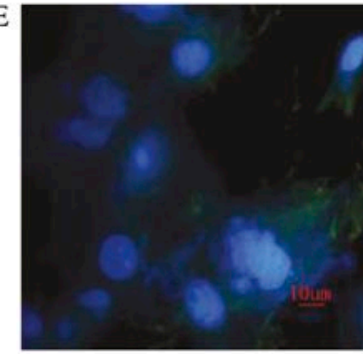

Figure 3. Adenosine induces HepG2 cell apoptosis in a time-dependent manner. HepG2 cells were treated with 2.0 mmol/1 adenosine for different times (range, 0-48 h). The nuclei stained by DAPI were observed by a fluorescence microscope. (A) Control; (B) 12; (C) 24 ; (D) 36 ; (E) 48 h.

followed by incubation with primary antibodies against $\beta$-actin (1:2000), caspase-4 (1:500), caspase-3 (1:1000), JNK (1:1000) or $\mathrm{CHOP}(1: 500)$, at $4^{\circ} \mathrm{C}$ overnight. The next day, the membranes were incubated with a biotin-conjugated secondary antibody for $60 \mathrm{~min}$ at room temperature, followed by incubation with an avidin-biotin-horseradish peroxidase complex at room temperature for $30 \mathrm{~min}$. The bands were visualized by an ECL detection system. The band intensity was measured with the Quantity One software (Bio-Rad, USA).

Statistical analysis. Data are presented as the means \pm SD of at least three independent experiments. Results were analyzed with the unpaired Student's t-test or one way ANOVA for different groups in SPSS 16.0. A p $<0.05$ was considered to indicate statistical significant differences.

\section{Results}

Adenosine inhibits HepG2 cell proliferation. To confirm that adenosine is cytotoxic to HepG2 cells, we used the MTT assay to evaluate the relative cell viability. HepG 2 cells were exposed to different concentrations of adenosine for $36 \mathrm{~h}$. The number of viable cells in the cell groups treated with 0.5, 1.0, 2.0, 4.0, $6.0 \mathrm{mmol} / 1$ adenosine decreased by $13.48 \pm 0.12,27.92 \pm 0.25$, $35.21 \pm 0.42,51.46 \pm 0.24$ and $71.42 \pm 0.58 \%$, respectively (Fig. 1, $\mathrm{p}<0.05)$. These results demonstrate that adenosine exerts cytotoxicity to HepG2 cells in a dose-dependent manner.

Adenosine induces HepG2 cell apoptosis as assessed by DAPI staining and the FCM assay. Cell death can be divided into necrosis and apoptosis based on morphological changes. 


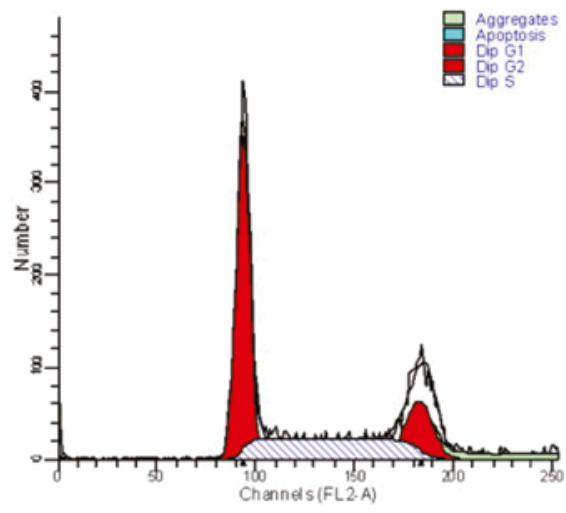

A

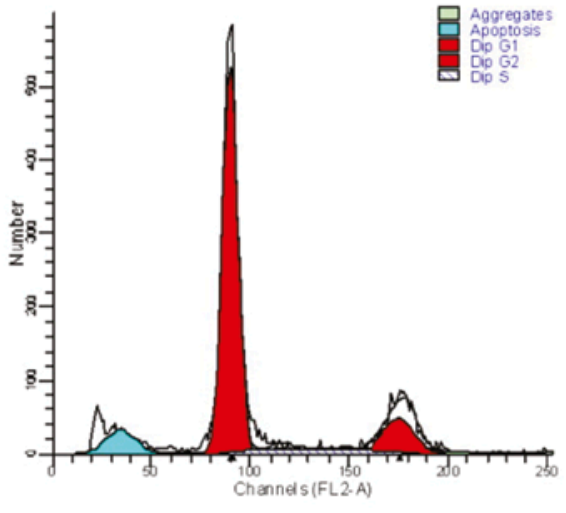

$\mathrm{B}$

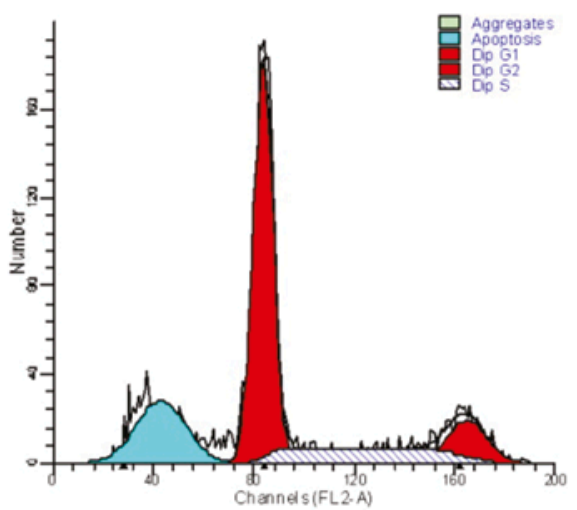

$\mathrm{C}$

Figure 4. Effects of adenosine on HepG2 cell cycle progression assessed by the FCM assay. Cell cycle phases were determined by propidium iodine staining, followed by flow cytometric analysis. (A) Control group; (B) $2.0 \mathrm{mmol} / 1$ adenosine for $12 \mathrm{~h}$; (C) $2.0 \mathrm{mmol} / \mathrm{l}$ adenosine for $24 \mathrm{~h}$. The percentages of cells in the sub-G1, G0-G1, S and G2-M phases were analyzed by the WinMDI 2.9 software. The percentages of apoptotic cells were $0.73 \pm 0.02 \%, 7.85 \pm 0.12 \%$ and $20.71 \pm 0.24 \%$, respectively.

CHOP
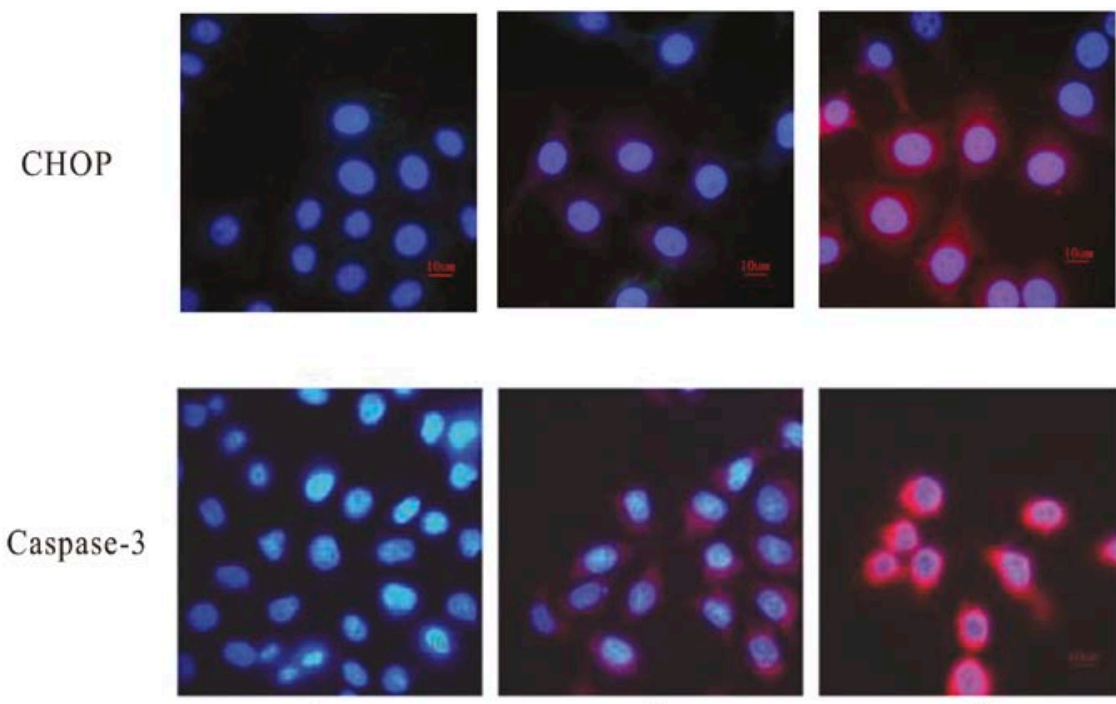

A

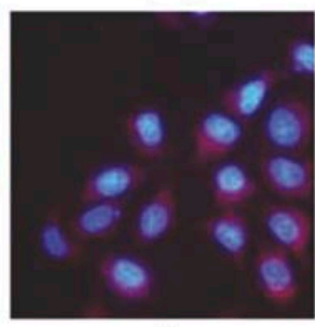

B

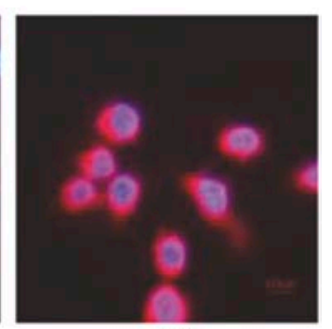

C

Figure 5. Effects of adenosine on CHOP and caspase-3 protein expression and their translocation determined by the immunofluorescence assay. HepG2 cells were exposed to normal medium or to $2.0 \mathrm{mmol} / 1$ adenosine for $36 \mathrm{~h}$. Caspase-3 subcellular localization was observed under a fluorescence microscope. (A) Blank group (normal culture medium with the primary antibody replaced by PBS); (B) Control group (normal culture medium); (C) the $2.0 \mathrm{mmol} / 1$ adenosine treatment group.

The morphologic hallmarks of apoptosis include chromatin margination, nuclear condensation and fragmentation. DAPI, a nuclear morphology indicator, nuclear factor and early indicator of cell death (30), was used to evaluate the size and roundness of the nucleus. We examined the cell nuclei morphological features after treatment with different concentrations $(0-4.0 \mathrm{mmol} / \mathrm{l})$ of adenosine for $36 \mathrm{~h}$ or after treatment with $2.0 \mathrm{mmol} / \mathrm{l}$ adenosine for different time-points $(0-48 \mathrm{~h})$. Normal nuclei were uniform in the control group (Figs. 2A and $3 \mathrm{~A}$ ), while with increases in the adenosine concentration or with prolongation of the treatment time, the nuclei became condensed and rounded and shrinkage occured (Figs. 2B and $\mathrm{C}$, and $3 \mathrm{~B}$ and $\mathrm{C}$ ). Nuclei fragmentation was obvious at higher doses or at later time-points (Figs. 2D and E, and 3D and E). These results demonstrate the occurrence of cell apoptosis. To obtain further evidence for apoptosis, the cell cycles were analyzed by FCM and the sub-G1 DNA content was used to indicate the cell percentage of apoptosis. The results showed that the percentages of apoptotic cells at 0,12 and $24 \mathrm{~h}$ were $0.73 \pm 0.02,7.85 \pm 0.12$ and $20.71 \pm 0.24 \%$, respectively (Fig. 4; $\mathrm{p}<0.05)$.

Effects of adenosine on CHOP and caspase-3 sub-cellular localization. The immunofluorescence assay was used to explore the sub-cellular localization of CHOP and caspase-3. The results showed that $\mathrm{CHOP}$ and caspase- 3 were diffused in the cytoplasm mainly in HepG2 cells of the control group (Fig. 5B); adenosine caused CHOP and caspase-3 translocation from the cytoplasm to the nucleus (Fig. 5C).

Effects of adenosine on GRP78, CHOP, JNK, caspase-4 and caspase-3 protein expression. To verify whether adenosine- 
A

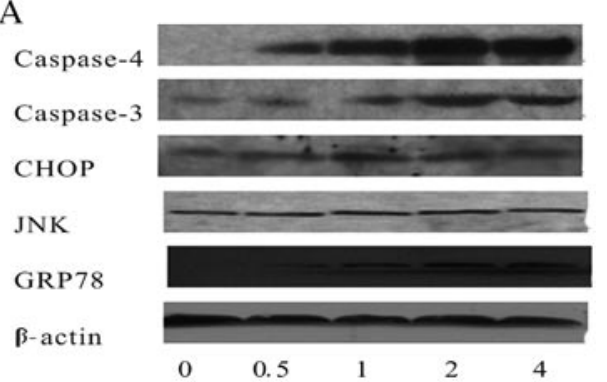

Adenosine concentration $(\mathrm{mmol} / \mathrm{l})$
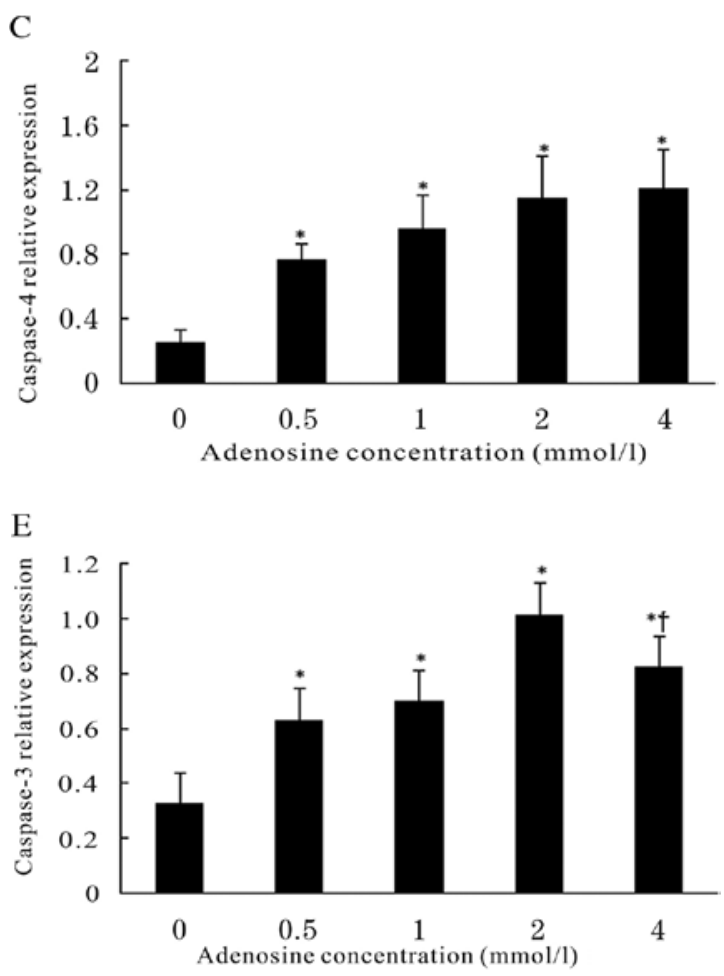

induced cell apoptosis was related to CHOP, GRP78, JNK, caspase-4 and caspase-3, Western blotting was used to detect their protein expression. As showed in Fig. 6A, CHOP, GRP78, caspase- 4 and caspase-3 protein expression increased in a dosedependent manner, compared to the control group (Fig. 6B, C, $\mathrm{D}$ and $\mathrm{E} ; \mathrm{p}<0.05)$. However, JNK protein expression did not differ between the control and adenosine treatment groups $(\mathrm{p}>0.05)$.

\section{Discussion}

Induction of cancer cell apoptosis is the major strategy for the development of chemotherapy drugs (31). In previous studies, adenosine-induced apoptosis in several tumor cell lines has been demonstrated. The mitochondrial pathway has been shown to be involved in adenosine-induced cell apoptosis in human colonic cancer Caco-2 cells (11) and human breast cancer cells (32). The death receptor pathway has been reported to be involved in 8-chloro-adenosine-induced cell apoptosis in BEL-7402 human hepatoma cells (33-35). However, the role of ERS in the adenosine-induced cell apoptosis has not been elucidated.
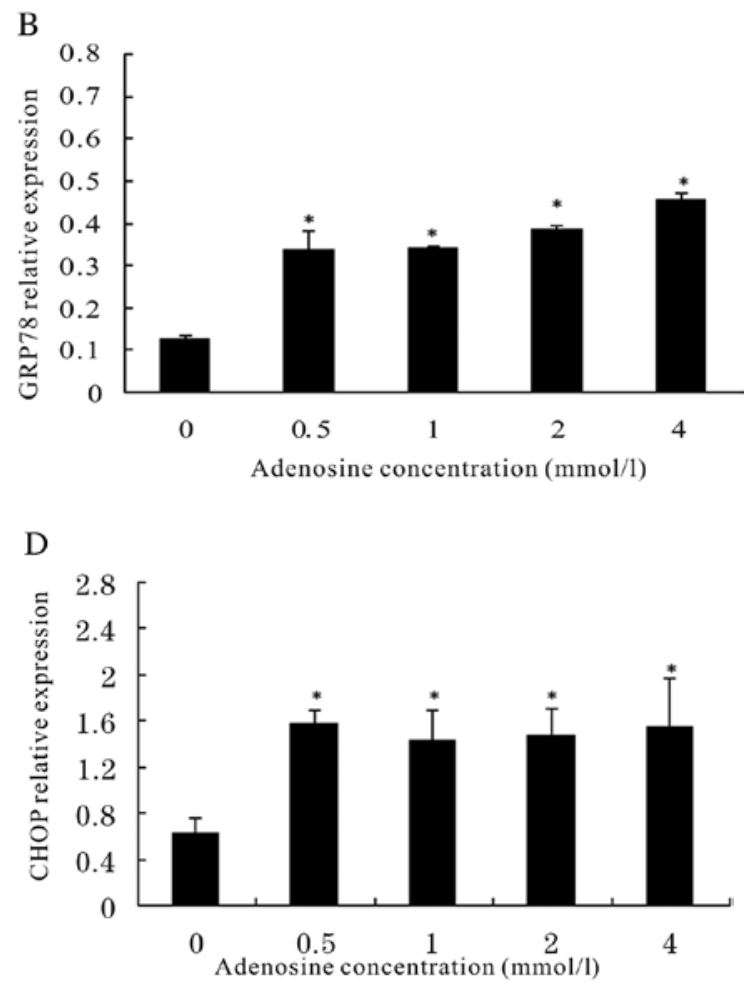

Figure 6. Effects of different adenosine concentrations on GRP78, caspase-4, caspase-3, CHOP and JNK protein expression. (A) Protein expression was assessed by Western blotting; Densitometry analysis of the relative protein expression of (B) GRP78, (C) caspase-4, (D) CHOP, and (E) caspase-3. The band intensity analysis was performed with the Quantity One Software; ${ }^{*} \mathrm{p}<0.05$ vs. the control group, ${ }^{\dagger} \mathrm{p}<0.05$ vs. the $1 \mathrm{mmol} / 1$ adenosine group. The values represent the means $\pm \mathrm{SD}$ of three independent experiments.

Adenosine-induced HepG2 cell apoptosis has been demonstrated in our previous studies $(12,13)$ and by others $(10,29)$. The typical morphological hallmarks of apoptosis include nuclear condensation, nuclear fragmentation and the formation of apoptotic bodies in the absence of an inflammatory reaction (35). In the present study, we verified that adenosine inhibited HepG 2 cell proliferation in a dose-dependent manner by means of the MTT assay. Our results also demonstrate that the nuclei of HepG2 cells displayed apoptotic morphological changes with the increases in the adenosine concentration or with prolongation of the treatment time (Figs. 2 and 3). FCM analysis further confirmed that the percentage of sub-G1 phase cells increased after adenosine treatment in a time-dependent manner (Fig. 4). These results support that adenosine inhibits HepG2 cell proliferation through inducing apoptosis, which is consistent with previous studies $(12,29)$.

GRP78 (referred as immunoglobulin heavy chain binding protein, $\mathrm{BiP}$ ), is a family member of the molecular chaperones and $\mathrm{Ca}^{2+}$-binding stress proteins located in the ER (36). GRP78 was reported as an ERS hallmark in previous studies $(17,37)$. Under normal conditions, the majority of the GRP78 protein is bound to three ER-localized protein sensors, PERK, ATF6 
and IRE1. Free GRP78 is kept at low concentrations. When the ERS occurs, the unfolded proteins combine with free GRP78. The depletion of free GRP78 is key for the dissociation of GRP78 from its transducer clients, thus leading to their activation. On the other hand, cells can up-regulate the expression of GRP78 to decrease the dissociation and activation. It has been reported that the expression of GRP78 increases in ERS-induced apoptosis $(17,20)$. In the present study, we also observed the expression of GRP78 increased (Fig. 6A and B), which supports the occurrence of ERS after treatment of HepG2 cells with adenosine.

CHOP (CCAAT/enhancer-binding protein homologous protein, also known as growth arrest and DNA damage-inducible protein) is a transcription factor which is up-regulated and plays a critical role in ERS-mediated apoptosis $(17,38)$. The fact that overexpression of CHOP results in growth arrest and apoptosis has been demonstrated in a rat model (39) and in HL-60 cells (40). Translocation of CHOP from the cytoplasm to the nucleus could regulate the expression of ERS-related genes $(17,43)$. Furthermore, it has been demonstrated that CHOP gene inhibition by drugs or knockout can protect cells from apoptosis mediated by ERS $(41,42)$. Previous studies have demonstrated that CHOP-regulated genes, such as DR5 (44), TRB3 (45) and bcl-2 (46), are involved in the cytoplasm to the nucleus was also observed (Fig. 5) and CHOP protein expression was up-regulated in a dose-dependent manner (Fig. 6A and D). In our previous study, adenosine downregulated bcl-2 expression (13). However, the mechanism by which CHOP regulates its downstream target genes and leads to cell apoptosis needs further study.

Cascade activation of caspases, such as caspase-3, caspase-8 and caspase-9 play an important role in apoptosis (47-49). Caspase-12, an ER-resident caspase, has been shown to be involved in ERS-mediated apoptosis $(50,51)$. However, human mature caspase-12 protein can not be produced because the gene is interrupted by a frame shift and a premature stop codon. Thus, human caspase-12 does not execute a function in ERS-induced apoptosis (52). Caspase-4, another caspase-1 family member, has the same function as caspase-12 in ERS-induced apoptosis in humans (53). Up-regulation of caspase-4 has been demonstrated in ERS-mediated apoptosis in human bronchial epithelial cells (54), human neuroblastoma SKN-SH cells and human esophageal squamous carcinoma EC109 and EC9706 cells (55). Caspase-3 is believed to be the main executioner caspase and is up-regulated in most apoptotic processes. As an executioner, caspase- 3 can be activated by other activated caspases such as caspase- $4,-8$ and -9 , and subsequently cleaves some specific substrates, such as PARP (56). In the present study, caspase-4 was obviously increased after treatment with adenosine. Furthermore, caspase-3 was up-regulated in a dose-dependent manner and its expression peaked at $2.0 \mathrm{mmol} / \mathrm{l}$ adenosine, which shows that caspase- 4 may activate caspase-3. However, the caspase-3 expression decreased after treatment with $4.0 \mathrm{mmol} / 1$ adenosine. Whether this observation is related to caspase- 3 being cleaved at the active segment, as reported in our previous studies (13), or to the increase in necrotic cells leading to a caspase-3 decrease need to be further investigated.

Activation of JNK pathway is a common phenomenon in stress-induced apoptosis in response to stress stimuli (57). To delineate the role of JNK in adenosine-mediated apoptosis, we detected the JNK expression by Western blotting. However, the results demonstrate that adenosine has no effects on JNK expression in HepG2 cells.

In summary, the present study demonstrated that GRP78, CHOP, caspase- 4 and caspase- 3 were up-regulated after adenosine treatment. The ERS pathway may be involved in the adenosine-induced HepG2 cell apoptosis.

\section{Acknowledgements}

This study was supported by grants from the National Nature Science Foundation of China (no. 30972925).

\section{References}

1. Saraste A and Pulkki K: Morphologic and biochemical hallmarks of apoptosis. Cardiovasc Res 45: 528-537, 2000.

2. Krysko DV, Vanden Berghe T, D'Herde K and Vandenabeele P: Apoptosis and necrosis: detection, discrimination and phagocytosis. Methods 44: 205-221, 2008.

3. Guan L, Han B, Li Z, et al: Sodium selenite induces apoptosis by ROS-mediated endoplasmic reticulum stress and mitochondrial dysfunction in human acute promyelocytic leukemia NB4 cells. Apoptosis 14: 218-225, 2009.

4. Zheng F, Ruan F, Xie XK and Liu SY: Apoptosis of drugresistant human ovarian carcinoma cell line COC1/DDP induced by survivin antisense oligonucleotides. Chin Med J (Engl) 119: 1572-1575, 2006.

5. Xu B and Liu P: 5-FU pretreatment potentiates cisplatininduced apoptosis through up-regulation of thrombospondin-1 in head and neck squamous cell carcinomas. Cancer Chemother Pharmacol 63: 1181-1183, 2009.

6. Fredholm BB: Adenosine, an endogenous distress signal, modulates tissue damage and repair. Cell Death Differ 14: 1315-1323, 2007.

7. Seetulsingh-Goorah SP: Mechanisms of adenosine-induced cytotoxicity and their clinical and physiological implications. Biofactors 27: 213-230, 2006.

8. Minelli A, Bellezza I, Tucci A, Rambotti MG, Conte C and Culig Z: Differential involvement of reactive oxygen species and nucleoside transporters in cytotoxicity induced by two adenosine analogues in human prostate cancer cells. Prostate 69: 538-547, 2009.

9. Sun W, Khoo HE and Tan CH: Adenosine induced apoptosis in BHK cells via $\mathrm{P} 1$ receptors and equilibrative nucleoside transporters. J Biochem Mol Biol 38: 314-319, 2005.

10. Yang D, Yaguchi T, Yamamoto H and Nishizaki T: Intracellularly transported adenosine induces apoptosis in $\mathrm{HuH}-7$ human hepatoma cells by downregulating c-FLIP expression causing Caspase-3/-8 activation. Biochem Pharmacol 73: 1665-1675, 2007.

11. Yasuda Y, Saito M, Yamamura T, Yaguchi T and Nishizaki T: Extracellular adenosine induces apoptosis in Caco-2 human colonic cancer cells by activating caspase-9/-3 via A(2a) adenosine receptors. J Gastroenterol 44: 56-65, 2009.

12. Wu LF, Li GP, Feng JL and Pu ZJ: Molecular mechanisms of adenosine-induced apoptosis in human HepG2 cells. Acta Pharmacol Sin 27: 477-484, 2006.

13. Wu LF, Li GP, Su JD, Pu ZJ, Feng JL, Ye YQ and Wei BL: Involvement of NF-kappaB activation in the apoptosis induced by extracellular adenosine in human hepatocellular carcinoma HepG2 cells. Biochem Cell Biol 88: 705-714, 2010.

14. Schroder M: Endoplasmic reticulum stress responses. Cell Mol Life Sci 65: 862-894, 2008.

15. Takuma K, Yan SS, Stern DM and Yamada K: Mitochondrial dysfunction, endoplasmic reticulum stress, and apoptosis in Alzheimer's disease. J Pharmacol Sci 97: 312-316, 2005.

16. Lin SS, Huang HP, Yang JS, et al: DNA damage and endoplasmic reticulum stress mediated curcumin-induced cell cycle arrest and apoptosis in human lung carcinoma A-549 cells through the activation caspases cascade- and mitochondrial-dependent pathway. Cancer Lett 272: 77-90, 2008.

17. Zou CG, Cao XZ, Zhao YS, et al: The molecular mechanism of endoplasmic reticulum stress-induced apoptosis in PC-12 neuronal cells: the protective effect of insulin-like growth factor I. Endocrinology 150: 277-285, 2009. 
18. Brewster JL, Linseman DA, Bouchard RJ, et al: Endoplasmic reticulum stress and trophic factor withdrawal activate distinct signaling cascades that induce glycogen synthase kinase-3 beta and a caspase-9-dependent apoptosis in cerebellar granule neurons. Mol Cell Neurosci 32: 242-253, 2006.

19. Biagioli M, Pifferi S, Ragghianti M, Bucci S, Rizzuto R and Pinton P: Endoplasmic reticulum stress and alteration in calcium homeostasis are involved in cadmium-induced apoptosis. Cell Calcium 43: 184-195, 2008

20. Li Z, Zhang T, Dai H, et al: Endoplasmic reticulum stress is involved in myocardial apoptosis of streptozocin-induced diabetic rats. J Endocrinol 196: 565-572, 2008.

21. Rasheva VI and Domingos PM: Cellular responses to endoplasmic reticulum stress and apoptosis. Apoptosis 14: 996-1007, 2009.

22. Kitamura M: Endoplasmic reticulum stress and unfolded protein response in renal pathophysiology: Janus faces. Am J Physio Renal Physiol 295: 323-334, 2008.

23. Shu CW, Sun FC, Cho JH, et al: GRP78 and Raf-1 cooperatively confer resistance to endoplasmic reticulum stress-induced apoptosis. J Cell Physiol 215: 627-635, 2008.

24. Kim I, Xu W and Reed JC: Cell death and endoplasmic reticulum stress: disease relevance and therapeutic opportunities. Nat Rev Drug Discov 7: 1013-1030, 2008.

25. Oyadomari S, Araki E and Mori M: Endoplasmic reticulum stress-mediated apoptosis in pancreatic beta-cells. Apoptosis 7: 335-345, 2002.

26. Kim SJ, Zhang Z, Hitomi E, Lee YC and Mukherjee AB: Endoplasmic reticulum stress-induced Caspase-4 activation mediates apoptosis and neurodegeneration in INCL. Hum Mol Genet 15: 1826-1834, 2006.

27. Qiao HX, Hao CJ, Li Y, et al: JNK activation mediates the apoptosis of xCT-deficient cells. Biochem Biophys Res Commun 370: 584-588, 2008

28. Yukioka F, Matsuzaki S, Kawamoto K, et al: Presenilin-1 mutation activates the signaling pathway of Caspase- 4 in endoplasmic reticulum stress-induced apoptosis. Neurochem Int 52: 683-687, 2008

29. Hermes M, Osswald H and Kloor D: Role of S-adenosylhomocysteine hydrolase in adenosine-induced apoptosis in HepG2 cells. Exp Cell Res 313: 264-283, 2007.

30. Daniel B and DeCoster MA: Quantification of sPLA2-induced early and late apoptosis changes in neuronal cell cultures using combined TUNEL and DAPI staining. Brain Res Brain Res Protoc 13: 144-150, 2004

31. Chiang PC, Chien CL, Pan SL, et al: Induction of endoplasmic reticulum stress and apoptosis by a marine prostanoid in human hepatocellular carcinoma. J Hepatol 43: 679-686, 2005.

32. Hashemi M, Karami-Tehrani F, Ghavami S, Maddika S and Los M: Adenosine and deoxyadenosine induces apoptosis in oestrogen receptor-positive and -negative human breast cance cells via the intrinsic pathway. Cell Prolif 38: 269-285, 2005

33. Wang M, Liu Y, Liu S and Zheng D: 8-Chloro-adenosine sensitizes a human hepatoma cell line to TRAIL-induced apoptosis by caspase-dependent and -independent pathways. Oncol Rep 12: 193-199, 2004

34. Wang MJ, Liu YX,Zhang JC, Liu SL and Zheng DX: Mechanisms of sensitization by 8-chloro-adenosine of human tumor cells to TRAIL-induced apoptosis. Zhonghua Zhong Liu Za Zhi 27: 586-590, 2005 (In Chinese).

35. Saraste A: Morphologic criteria and detection of apoptosis. Herz 24: 189-195, 1999.

36. Chen Y, Liu CP, Xu KF, et al: Effect of taurine-conjugated ursodeoxycholic acid on endoplasmic reticulum stress and apoptosis induced by advanced glycation end products in cultured mouse podocytes. Am J Nephrol 28: 1014-1022, 2008.

37. Lee AS: The ER chaperone and signaling regulator GRP78/ $\mathrm{BiP}$ as a monitor of endoplasmic reticulum stress. Methods 35 $373-381,2005$
38. Pino SC, O'Sullivan-Murphy B, Lidstone EA, et al: CHOP mediates endoplasmic reticulum stress-induced apoptosis in Gimap5-deficient T cells. PLoS One 4: e5468, 2009.

39. Liu HY, Qian J, Wang FH, et al: Endoplasmic reticulum stress participates in the cell apoptosis process in experimental retinal detachment. Zhonghua Yan Ke Za Zhi 44: 800-806, 2008 (In Chinese)

40. Li J, Xia X, Ke Y, Nie H, Smith MA and Zhu X: Trichosanthin induced apoptosis in HL-60 cells via mitochondrial and endoplasmic reticulum stress signaling pathways. Biochim Biophys Acta 1770: 1169-1180, 2007.

41. Gotoh T, Oyadomari S, Mori K and Mori M: Nitric oxideinduced apoptosis in RAW 264.7 macrophages is mediated by endoplasmic reticulum stress pathway involving ATF6 and CHOP. J Biol Chem 277: 12343-12350, 2002.

42. Kim KM, Pae HO, Zheng M, Park R, Kim YM and Chung HT: Carbon monoxide induces heme oxygenase-1 via activation of protein kinase R-like endoplasmic reticulum kinase and inhibits endothelial cell apoptosis triggered by endoplasmic reticulum stress. Circ Res 101: 919-927, 2007.

43. Wang XZ, Kuroda M, Sok J, et al: Identification of novel stressinduced genes downstream of chop. EMBO J 17: 3619-3630, 1998.

44. Yamaguchi $\mathrm{H}$ and Wang HG: CHOP is involved in endoplasmic reticulum stress-induced apoptosis by enhancing DR5 expression in human carcinoma cells. J Biol Chem 279: 45495-45502, 2004.

45. Ohoka N, Yoshii S, Hattori T, Onozaki K and Hayashi H: TRB3, a novel ER stress-inducible gene, is induced via ATF4-CHOP pathway and is involved in cell death. EMBO J 24: 1243-1255, 2005.

46. McCullough KD, Martindale JL, Klotz LO, Aw TY and Holbrook NJ: Gadd153 sensitizes cells to endoplasmic reticulum stress by down-regulating $\mathrm{Bcl} 2$ and perturbing the cellular redox state. Mol Cell Biol 21: 1249-1259, 2001.

47. Kaufmann SH, Lee SH, Meng XW, et al: Apoptosis-associated caspase activation assays. Methods 44: 262-272, 2008.

48. Mazumder S, Plesca D and Almasan A: Caspase-3 activation is a critical determinant of genotoxic stress-induced apoptosis. Methods Mol Biol 414: 13-21, 2008.

49. Mazzoni $\mathrm{C}$ and Falcone C: Caspase-dependent apoptosis in yeast. Biochim Biophys Acta 1783: 1320-1327, 2008

50. Lien YC, Kung HN, Lu KS, Jeng CJ and Chau YP: Involvement of endoplasmic reticulum stress and activation of MAP kinases in beta-lapachone-induced human prostate cancer cell apoptosis. Histol Histopathol 23: 1299-1308, 2008.

51. Liu G, Sun Y, Li Z, et al: Apoptosis induced by endoplasmic reticulum stress involved in diabetic kidney disease. Biochem Biophys Res Commun 370: 651-656, 2008.

52. Fischer H, Koenig U, Eckhart L and Tschachler E: Human caspase 12 has acquired deleterious mutations. Biochem Biophys Res Commun 293: 722-726, 2002.

53. Hitomi J, Katayama T, Eguchi Y, et al: Involvement of Caspase-4 in endoplasmic reticulum stress-induced apoptosis and Abetainduced cell death. J Cell Biol 165: 347-356, 2004.

54. Tagawa Y, Hiramatsu N, Kasai A, et al: Induction of apoptosis by cigarette smoke via ROS-dependent endoplasmic reticulum stress and CCAAT/enhancer-binding protein-homologous protein (CHOP). Free Radic Biol Med 45: 50-59, 2008.

55. Liang B, Song X, Liu G, et al: Involvement of TR3/Nur77 translocation to the endoplasmic reticulum in ER stress-induced apoptosis. Exp Cell Res 313: 2833-2844, 2007.

56. Shu B, Duan W, Yao J, Huang J, Jiang Z and Zhang L: Caspase 3 is involved in the apoptosis induced by triptolide in HK-2 cells. Toxicol In Vitro 23: 598-602, 2009.

57. Cui J, Zhang M, Zhang YQ and $\mathrm{Xu} Z \mathrm{ZH}$ : JNK pathway: diseases and therapeutic potential. Acta Pharmacol Sin 28: 601-608, 2007. 